The Promotion of Self-Regulation through Parenting Interventions

\author{
Matthew R. Sanders \\ Parenting and Family Support Centre, The University of Queensland
}

Trevor G. Mazzucchelli

School of Psychology and Speech Pathology, Curtin University and Parenting and Family

Support Centre, The University of Queensland

Word count: 9,974 


\begin{abstract}
The capacity for a parent to self-regulate their own performance is argued to be a fundamental process underpinning the maintenance of positive, nurturing, non-abusive parenting practices that promote good developmental and health outcomes in children. Deficits in self-regulatory capacity which have their origins in early childhood are common in many psychological disorders and strengthening self-regulation skills is widely recognised as an important goal in many psychological therapies and is a fundamental goal in preventive interventions. Attainment of enhanced self-regulation skills enables individuals to gain a greater sense of personal control and mastery over their life. This paper illustrates how the self-regulatory principles can be applied to parenting and family-based interventions at the level of the child, parent, practitioner and organisation. The Triple $\mathrm{P}-\mathrm{Positive}$ Parenting Program, which uses a self-regulatory model of intervention, is used an example to illustrate the robustness and versatility of the self-regulation approach to all phases of the parent consultation process.
\end{abstract}




\section{The Promotion of Self-Regulation through Parenting Interventions}

A parent's capacity to change their own behaviour in response to cues and information about the current needs of their children is fundamental to successful adaptation to the role of being a parent. Although a parent's approach to raising their children is strongly rooted in the social, economic and cultural context surrounding parenthood, ultimately individual parents have the capacity to decide how they wish to raise their children. Parents can determine the specific behaviours, skills and values they wish to promote, and the methods of parenting they adopt including how they will encourage desirable behaviours and discourage problem behaviours (e.g., limit setting and methods of disciplining their children).

The rationale for focusing on self-regulation is compelling. First, the capacity for selfregulation is associated with various positive life outcomes such as academic achievement, income, savings behaviour, physical and mental health, better interpersonal relationships and happiness (e.g., Duckworth \& Seligman, 2005; Mischel, Shoda, \& Peake, 1988; Moffitt et al., 2011; Shoda, Mischel, \& Peake, 1990; Tangney, Baumeister, \& Boone, 2004; Tsukavama, Toomey, Faith, \& Duckworth, 2010). Second, deficits in self-regulation are found in a large number of personal and social problems and psychological disorders including aggression, anxiety, criminal behaviour, depression, and impulse control problems such as binge eating and alcohol abuse (e.g., Avakame, 1998; Baumeister, Heatherton, \& Tice, 1994; Moffitt et al., 2011; Tangney et al., 2004; Tremblay, Boulerice, Arseneault, \& Niscale, 1995). Third, self-regulation seems to be an important mechanism in the success of many psychological interventions including acceptance and commitment therapy (ACT, Hayes, Stroshal, \& Wilson, 1999), behavioural activation (BA; Martell, Addis, \& Jacobson 2001; Martell, Dimidjian, Herman-Dunn, 2010), dialectical behaviour therapy (DBT, Linehan, 1993), problem solving therapy (Nezu, 1986) and self-control therapy (Rehm, 1977) and in some positive psychology interventions (Kashdan \& Rottenberg, 2010; Mazzucchelli, Kane, \& 
Rees, 2010). Finally, deficits in self-regulation in early childhood predict adult health, economic and social behaviour (Moffitt et al., 2011).

The capacity to change one's parenting behaviour in a planned, self-initiated and deliberate way involves parents recognising that a change in their behaviour may be necessary. Sometimes the changes required of parents can be relatively minor, such as attending more frequently to a specific child behaviour they wish to encourage, while other changes can be more difficult to execute such as refraining from reacting to problem behaviour. Self-initiated change involves a complex but ill-defined interplay of cognitive, behavioural and affective processes; these changes include the capacity to plan and anticipate, to regulate one's own emotions, to solve problems, and where necessary to collaborate with significant others involved in the care or education of children (e.g., partners, child carers, teachers, grandparents). It also involves a set of planned actions, the execution of the plan, a review of whether the plan worked and, if necessary, further tailoring of the plan until the goal is attained. Despite the hypothesised importance of self-regulation to parenting (see Moffitt et al., 2011) little attention has been devoted to the issue of reliably measuring parents' capacity to self-regulate or to promote self-initiated behaviour change. This paper seeks to fill that gap by defining the concept of parental self-regulation, by discussing the theoretical basis of the construct, and the clinical application and empirical basis of parental self-regulation. Finally we discuss the implications of self-regulation for practice, policy and future research on parenting intervention.

Although this paper focuses particularly on parental self-regulation, the ultimate goal is to build children's self-regulatory capacity so as to function optimally. It is suggested that parents modelling self-regulation and using specific parenting practices may best accomplish this goal. At the next level, to assist parents to acquire self-regulation, practitioners must model and use similar practices with parents. Further, the same self-regulatory principles 
also apply to organisations supporting practitioners delivering parenting interventions.

Consequently, in the course of our paper we attempt to illustrate that the self-regulatory principles can usefully be applied at all levels of the parent consultation process.

\section{Self-Regulation: A Unifying Framework for Strengthening Parenting}

We have argued previously that the development of an individual's capacity for selfregulation should be a central goal of parenting interventions (Sanders, 2008). Self-regulation is a process whereby individuals acquire the skills they need to change their own behaviour and become independent problem solvers and controllers of their own destiny. Capacity for self-regulation can be enhanced in a broader social environment that supports parenting and family relationships (Karoly, 1993). The approach to self-regulation discussed here is derived from social-cognitive theory. According to Bandura, the development of self-regulation is related to personal, environmental and behavioural factors; these factors operate separately but are interdependent (Bandura, 1986; Bandura, 1991). Self-regulation has an important role in the delay of gratification, emotional expression, moral development, compliance, adjustment, social competence, empathy and academic performance (Eisenberg, 2004). Social-cognitive learning is the route to developing good self-regulatory skills (Bandura, 1977b).

Bandura's cognitive social learning theory describes both the processes by which individuals can change their behaviour and the social interactional contexts that promote the capacity to change. Self regulation is usefully defined by Karoly (1993) as:

...those processes, internal and or transactional, that enable an individual to guide his/her goal-directed activities over time and across changing circumstances (contexts). Regulation implies modulation of thought, affect, behavior, or attention via deliberate or automated use of specific mechanisms and supportive metaskills. The processes of self-regulation are initiated when routinized activity is impeded or when goal 
directedness is otherwise made salient (e.g. the appearance of a challenge, the failure of habitual action patterns, etc). (p.25)

In the case of parents learning to change their parenting practices, the self-regulation process is operationalised as a multi-component process involving five key elements.

Self-management tools. Parents learn to utilise different tools and skills to change their parenting practices. These skills include self-determination of parenting goals (what changes parents seek to make), self-monitoring of specific parent and child behaviours over the course of an intervention (how often specific target behaviours occur), self-selection of change strategies (a specific parenting plan to execute), self-evaluation of whether a parent achieved some performance criterion (what they set out to achieve) and self-reward (parent congratulates themselves for goal attainment). In this approach each parent is responsible for choosing from a range of options introduced in a parenting program which aspects of their own and their child's behaviour they wish to change.

Parental self-efficacy. Many parenting interventions seek to increase parents’ confidence in their capacity to solve personally relevant problems. Parents of children with significant behavioural and emotional problems often enter parenting programs with low selfefficacy in their capacity to handle specific behaviours (e.g., aggression, tantrums, child's fearfulness). They also tend to have lower task specific self-efficacy in managing their daily parenting responsibilities (Sanders \& Woolley, 2005). Over the course of a parenting program parents' self-efficacy typically improves as they experience mastery and accomplish their goals. Parents develop global and task specific positive expectations that they have the knowledge and skill to change their child's and their own behaviour. Such positive expectations are associated with attempting to change behaviour in the future, persistence, and recovery from setbacks and disappointments (Bandura, 1977a, 1994). 
Personal agency. Parents develop explanations as to why change did or did not occur during a parenting intervention. A self-regulation approach encourages parents to "own" the change process. This involves encouraging parents to attribute changes or improvements in their family situation to their own or their child's efforts rather than to chance, age, maturational factors, the practitioner's skills or efforts or other uncontrollable events (e.g., a spouse's poor parenting or genes). It is tempting for practitioners to feel reassured and pleased when a parent says that their child is so much better since coming to see the therapist. The practitioner should prompt the parent to identify what they are doing differently that has enabled the child's behaviour to change.

Self-sufficiency. The ultimate goal of a parenting intervention is that the parent becomes an independent problem solver who has the personal resources, knowledge and skills to maintain any gains achieved and to tackle future problems with the same child or other children in the family. Self-sufficient parents are not heavily reliant on others to successfully execute their daily parenting responsibilities and have the necessary resilience and personal resources to parent effectively with minimal or no additional support from services or social networks. This pursuit of self-sufficiency does not mean that parenting is undertaken in a disconnected way from essential support networks (e.g., childcare, good health care) or is viewed as an insular, private activity even though most parenting is undertaken in the privacy of peoples' homes. On the contrary, parents are encouraged to build healthy support networks including extended family support and other people from within their community. However parents are encouraged to view most of the key parenting decisions they take with their children as their own responsibility and as an exercise of personal judgement and choice.

Problem solving. Successful parenting requires parents to become troubleshooters and active problem solvers. Intervention equips parents to define problems more clearly, 
formulate options, develop a parenting plan, execute the plan, and evaluate the outcomes achieved and to revise the plan as required. However, an intervention process needs to assist parents to generalise the knowledge, principles and skills they have learned so they can apply them to future problems, at different points in a child's later development, and to other relevant siblings in a family.

These self-regulation principles are very robust and apply equally to all program participants including parents and children, service providers, disseminators, program developers and researchers. The self-regulation skills outlined above can be taught to children by parents in developmentally appropriate ways. For instance, attending and responding to child-initiated interactions and prompting, modeling and reinforcing children's problem solving efforts promotes emotional self-regulation, independence, and problem solving in children. Self-regulation principles can also be applied in the training of service providers to deliver different levels of the intervention, in troubleshooting implementation difficulties, or staffing problems within an organisation (Sanders \& Turner, 2005).

\section{Parental Self-Regulation in Action: Towards an Operational Definition}

In order to further operationalise the concept of self-regulation as it applies to parenting it is useful to consider the characteristics of a parent who has strong self-regulatory capability. Such a parent would have a clear sense of the sorts of behaviours, skills and values she wishes to manifest in herself as a parent and adult, instil in her child, and foster in her home and broader community. She would have realistic expectations of herself, of others in a caring role for her child, and knowledge as to what she could reasonably expect of her child at different points of his or her development. Monitoring her performance against these standards would be automatic, rather than conscious or deliberate (Papies \& Aarts, 2011). 
Upon detecting a discrepancy between a personal standard and current performance (be it performance of herself, her child, or a significant other), goal-relevant habitual behaviour would be brought under her volitional control. Deliberately attending to these behaviours would provide information from which she develops hypotheses as to why the discrepancy has come about and clarity with regard to her objectives. The parent would have a rich repertoire of knowledge and skills from which to draw on when formulating options and developing a plan or new way of responding. These would not only include parenting and interpersonal skills (such as clear instructions, descriptive praise, planned ignoring), but also personal management skills (such as verbal self-cueing, attentional control, and ideas on how to arrange her environment to prompt and reinforce her own behaviour). The parent would proceed to execute the plan and evaluate the outcome, revising the plan as required until a desirable outcome has been achieved. At this point the parent would allow the new behaviour(s) to come under the control of new environmental stimuli-that is, her behaviour would again become automatic.

The self-regulating parent would have positive expectations that she could successfully enact her plan and bring about future positive outcomes. She would be self-reflective, open to and capable of identifying personal strengths and weaknesses, successes and failures, without being unhelpfully critical. Her self-evaluations and attributions would be constructive and serve to increase her competence and confidence for addressing future challenges.

As parents attempt to achieve their goals, they are frequently confronted with potentially emotion-arousing situations. Affect is naturally linked to goal-directed behaviour. Diverse feeling states arise as a result of success, failure, frustration, slowing, or delay in the pursuit of goals (Carver \& Scheier, 2011). But feelings can also be elicited by stimuli as a result of respondent conditioning. The self-regulating parent would be capable of accepting, ignoring, or down-regulating emotions that might otherwise interfere with successful goal 
pursuit (Koole, van Dillen, \& Sheppes, 2011). However, and importantly, rather than ploughing through life with a stony grimness she would mostly enjoy the process. Having genuinely high self-regulatory capacity she would have the ability to deploy her conscious self-regulation skills when required and suspend them when they're not required. On occasion she would let go of her end-state-cognitions in order to enjoy the moment, experience contentment and flow (Csikszentmihalyi, 1990).

In summary, parents with strong self-regulatory capacity: (a) are self-sufficient in that they have the personal resources, knowledge and skills to parent effectively with minimal support from others; (b) show good self-management and problem solving skills, at times setting clear goals for their children, reflecting upon and evaluating their interactions, and selecting and implementing change strategies; (c) have a sense of agency, believing that they can influence their child's and their own behaviour; and (d) believe that they are able to implement behaviour change strategies and that good outcomes will occur as a result.

\section{Deficits in Parent Self-Regulation}

In contrast to this description of a parent with strong self-regulatory capacity, it is also illuminating to consider, from a self-regulatory perspective, the behaviour of parents of children with disruptive behaviour problems who resist change. Patterson and Chamberlain (1994) developed a model to describe and explain the avoidance behaviour that they observed when practitioners attempted to change these parents' parenting practices (see Figure 1). These parents said things like, "I won't do that, it won't work" or "I can't do that. It's hopeless," or, they nodded in agreement, said very little, and then failed to follow through with homework tasks. Patterson and Chamberlain speculated that these parents had a learning history of failure where day-after-day, week-after-week, and year-after-year they were unsuccessful in obtaining a compliant response from their child. This history accounted for the strong negative affect that parents displayed during discussions about discipline 
practices. Parents can express anger and contempt that their child's behaviour is so difficult, sadness that parenthood is not the happy experience they hoped it would be, and fear as to what's going to happen in the child's future — school drop-out, teenage pregnancy, drugs, crime. To avoid these unpleasant emotions, Patterson and Chamberlain suggested that parents may try to avoid future confrontations with their children, and as an extension of this, avoid practitioner efforts to support them to go back and try again. Eventually, parents may develop a story that explains why their child has difficult behaviour and doesn't respond to discipline and typically this explanation is likely to be removed from themselves. The story will implicate intrinsic characteristics of the child (e.g., "He's just like his father, he's inherited his father's genes"), or to their child's school or peers ("It's the school's fault, they should do something about it"), or to early sickness, rather than stemming from parent-child interactions.

From a self-regulatory perspective, Patterson and Chamberlain (1994) are describing parents who: (a) have underdeveloped or are unwilling to use their self-management skills, parents who are reluctant to set goals for their children or their own behaviour or find it difficult to reflect on and evaluate their interactions; (b) have low self-efficacy, parents who don't believe that they would be able to implement new strategies or that they would have good outcomes; (c) in terms of personal agency, parents who attribute their child's and their own behaviour to factors outside of their control; and (d) are low in terms of self-sufficiency, parents with a tendency to look to others to solve their problems.

Patterson and Chamberlain (1994) also found that there were other sources of parental resistance for these families including certain parental characteristics, such as being depressed, antisocial, and stressed, and contextual factors, such as whether parents were socially disadvantaged in various ways. Also, when a parenting intervention got under way, the behaviour of the practitioner became another source for resistance. Practitioners' efforts 
to either teach or confront increased the probability that the next reaction of the parent would be resistant. If the practitioner adopted a nondirective stance and didn't teach, the effect would be to radically reduce the level of resistance. Patterson and Chamberlain noted that a delicate balancing act is required where practitioners and interventions must find an optimal level of teaching and confronting for each individual parent or couple to move them to change their family management practices. Indeed, when practitioners attempt to help parents change their parenting practices, they are likely to encounter some unpleasant emotions and be faced with a variety of techniques for avoiding behaviour change. In fact, a practitioner's efforts to help parents may be effectively punished or extinguished by parents' behaviour. Given this, we suggest that it is very likely that the same model of resistance also applies to practitioners (see Figure 2).

\section{The Importance of Self-Regulation in Practitioners}

Practitioner resistance can be thought of as avoidance behaviour, expressed in terms of rewarding parents for resistant behaviour (e.g., by discussing irrelevant topics); avoiding managing resistance (e.g., failing to confront process issues such as arriving late to sessions); or blame (e.g., blaming parents for not doing their homework rather than understanding where the obstacles lie and troubleshooting ways to make compliance more likely). Practitioner resistance can be influenced by many factors including their history of working with parents and their emotions. Just like parents, practitioners have a history of interactions where they have attempted to change parent behaviour, but where, at times, they have not experienced success. When practitioners are prompted once again try to influence a parent's behaviour it can lead to some unpleasant emotions that they wish to avoid. Like parents, practitioners can develop unhelpful explanations for why parents behave the way they do. In summary, it is likely that practitioners can experience "resistance" like parents—it is understandable and normative. Practitioners need to be aware of these influences on their 
behaviour, seek support from colleagues and foster their own self-regulation skills to manage their emotions and behaviour.

\section{The Development of Self-Regulation}

The capacity for self-regulation including parental self-regulation emerges in a developmental context at a very young age. Emergence of self-regulation capacity in early childhood is a strong predictor of long-term developmental outcomes for children. For example, Moffitt et al. (2011) found that a composite measure of children's self-control (that included independent observation of children's behaviour) assessed at age three predicted a wide variety of indices of adult wellbeing at age thirty after controlling social class and the child's IQ. These outcomes included their physical health, their adult income, substance abuse and criminal behaviour. Furthermore, children who had improved their self-control by age 11 had significantly better longer-term developmental outcomes than children who had not, suggesting the possibility that improving self-control outcomes for children through early intervention could be a common pathway to prevention of a variety of adverse developmental outcomes in young people and adults.

Kopp (1982) has described the emergence of self-regulation abilities in young children. From birth infants modulate their arousal and exhibit reflexive patterns of behaviour such as hand-to-mouth movements that permit thumb sucking. From 3 months of age, infants can be observed changing their behaviour in response to events and stimuli in the environment (e.g., reaching and grasping). From between 9 and 12 months children begin to show an awareness of the social demands of caregivers and the ability to initiate, maintain, and cease behaviour accordingly. By 24 months, they show the ability to delay an act on request and to behave according to caregiver requests even in the absence of external monitors. At 36 months, children begin to show flexibility of control processes that meet changing situational demands and these processes continue to mature from this age. 
Neuroscientists study self-regulation as executive functions, or cognitive processes that manage other cognitive processes, such as working memory, inhibition and attention (Chan, Shum, Toulopoulou, \& Chen, 2008; Senn, Espy, \& Kaufmann, 2004). Inhibitory control and working memory are among the earliest functions to appear, with initial signs observed in infants, 7 to 12-months-old (Anderson, 2002; De Luca \& Leventer, 2008). From this age children display spurts in their performance in tasks of these and other executive functions, suggesting that the development of these functions does not necessarily occur in a linear fashion. Executive functioning development corresponds to the neurophysiological developments of the frontal lobes and other interconnected regions (Anderson, 2002; De Luca \& Leventer, 2008). Capacity for self-regulation has been demonstrated to be under both genetic and environmental influences (Bouchard, 2004) and genes associated with selfcontrol are beginning to be identified (Ebstein, 2006).

Although there may be some inherited elements, there is evidence that self-regulatory capacity is a learned skill and can be strengthened with practice and training (e.g., Gollwitzer, 1999; Muraven, Baumeister, \& Tice, 1999). There is also evidence that parental behaviours are associated with the development of self-regulatory capacity in children (e.g., Avakame, 1998; Finkenauer, Engels, \& Baumeister, 2005; Karreman, van Tuijl, van Aken, \& Dekovic, 2008; Sanders, 1998; Valiente, Lemery-Chalfant, \& Reiser, 2007). Building selfregulation capacity and skills in children is important and lays the foundation for selfregulatory capacity as an adult. If parents can help children develop self-regulatory skills, they will equip them with powerful and important life tools to alter their behaviour and responses and overcome undesirable genetic, peer and other social influences throughout life. Table 1 provides examples of specific parenting practices that, theoretically, should promote self-regulatory strategies in children and adolescents.

\section{Consulting Practices that Promote the Self-Regulation of Parents}


There are a range of ways parents can enhance children's self-regulation skills, but a parent's capacity to regulate his or her behaviour is essential to consistently model and apply these strategies. It is therefore important that parenting interventions enhance parents' own self-regulatory capacity.

The preceding discussion on parent and practitioner avoidance indicates how parents and practitioners reciprocally influence each other, potentially disrupting the acquisition of parenting skills and the change process. This, along with the importance of parents building their self-regulatory capacity, has implications for how a practitioner should interact with a parent over the course of an intervention. We propose that the goal of the practitioner should be to develop a collaborative relationship with the parent because this type of relationship is likely to be mutually positively reinforcing and increase the likelihood that the parent will acquire skills relevant to managing their own and their child's behaviour. Triple P recommend a range of consulting practices that aim to simultaneously build a collaborative relationship and enhance a parent's self-regulation skills.

Conveying respect in an emotionally supportive context. Practitioners need to respect parents and view the consultation process as a genuine sharing of knowledge and expertise. However, practitioners can anticipate that some of the materials discussed in consultation sessions are likely to generate unpleasant emotions at times. Of course, for behaviour change to occur, attention must be paid to those areas that are the focus of change. When parents experience unpleasant emotion practitioners need to empathically support parents to accept and manage the emotion before returning the focus to behaviour change and skills development. It is interesting to note that breaking patterns of experiential avoidance and modifying action tendencies in response to emotional dysregulation is an approach that has been emphasised in a number of newer behaviour therapies such as ACT, BA and DBT 
(Barlow, Allen, \& Choate, 2004) and may be considered an important component of selfregulation.

Building an optimistic outlook. It's important that practitioners convey optimism that change is possible. This can be done by using questions that presuppose that things will change for the better and that there are strategies that the parent can use to help build such preferred realities, "Which of these strategies are relevant to pursuing your goal?" These kinds of prompts are likely to help build parents' sense of self-efficacy.

Using a guided participation approach. Effective parent consultation involves creating conditions for independent problem solving. This may be achieved by using prompts to guide the discussion while simultaneously encouraging the full participation of the parent, "Can you think of any reasons why your child is hitting?... How could you manage it?... Do you see any similarities between this situation and the one we worked on in the last session?" This process uses self-discovery methods and encourages parents to take responsibility for their decisions (Sanders \& Lawton, 1993; Sanders, Mazzucchelli, \& Ralph, 2012).

Challenging beliefs about needing to be rescued. Sometimes parents express the desire for practitioners to just "fix" their child or they demand instant answers. It is important that practitioners don't fall into the trap of simply rescuing parents as this would foster dependency. Unfortunately, the risk is that this does not assist parents to learn how to resolve problems by themselves in the longer term. If practitioners notice this pattern it is useful to comment on it and challenge the parent to come up with solutions themselves. Practitioners then have the opportunity to listen, summarise and pick out a part that they can encourage.

Challenging self-defeating behaviour. During parent consultation, parents can exhibit a range self-defeating behaviours including the failure to complete homework, arriving late, off-topic conversations, being overtalkative, being overly upset. A partnership implies that 
both the parent and practitioner are doing their share; practitioners need to be prepared to challenge their partners when these sorts of problematic behaviours occur. Practitioners must be prepared to discuss how the behaviour is getting in the way of the parent's goals, develop an understanding as to why it's occurring, and prompt the parent to come up with ideas as to how to manage the difficulty. This process is similar to the functional analysis approaches adopted by other behavioural approaches such as DBT and BA and may equip parents with useful knowledge and skills for changing their own behaviour.

Establishing expectancies that promote self-regulation. By making expectations clear to parents before hand, it is easier for them to do what is expected of them, "When I ask how things went, I'd like you to tell me some aspects that worked well and some that didn't work so well" or "At this stage in the intervention I really expect you to be coming up with your own ideas as to how to manage your child's behaviour." The use of rules in this fashion can promote both self-regulation and collaboration (Malott, 1988).

\section{Specific Techniques that Promote the Self-Regulation of Parents}

In addition to the consulting practices described above, we propose a number of specific techniques that may be useful in promoting parental self-regulation.

Modelling. Parenting practitioners have an opportunity to demonstrate the skills that they wish to instil in parents. These include being organised and prepared for sessions, negotiating goals for the intervention as a whole and for each session, and monitoring and reviewing progress in a systematic fashion during sessions. When obstacles or problems arise practitioners can attempt to understand the difficulty in a nonjudgmental way, generate ideas to overcome the issue, formulate a plan and enact it before reviewing the outcome. All this can be done while conveying optimism that change is possible and encouragement for both the parent's and the practitioner's own efforts. 
Instruction in social learning principles. Parenting interventions based on social learning principles provide parents with explicit information regarding why children behave the way they do (e.g., Sanders, 1999; Webster-Stratton, 1998). These principles are then reinforced by instruction in how they may be applied in a parenting context through a range of adaptive parenting strategies. If parents have an understanding of these principles and strategies they may then recognise that these principles and strategies do not just apply to parents and children, but to all human behaviour including one's own.

Reinforce generalisation of parenting skills across settings and tasks. When practitioners notice or parents comment that they've generalised their parenting skills to different places or tasks, practitioners can comment, "So you found the behaviour correction routine not only works at home for destructive behaviour, but in the car for fighting too." Generalising skills is precisely what parents need to be doing to be self-sufficient and can be reinforced directly (see Stokes \& Baer, 1977).

Encouraging self-evaluation. Self-evaluation is an important part of self-regulation. Practitioners can encourage parents to attribute successes and failures to their own actions using least-to-most prompts like, "How did that go?... What did you do well?" (Sanders, Mazzucchelli et al., 2012).

Use a graduated prompting format to strengthen self-regulation skills. Parenting competence and self-regulatory capacity can be enhanced simultaneously through a feedback process that adopts a "least-to-most" structured prompting format (Sanders, Mazzucchelli, et al., 2012). In this model a parent's parenting and self-regulatory knowledge and skills are constantly assessed and the least amount of prompting and information is provided that is necessary for the parent to successfully manage their own performance. For instance, after practising a particular parenting skill, if a parent does not spontaneously evaluate his or her performance and identify goals for change, the practitioner would provide the least amount of 
prompting to assist them to constructively do so. Over successive sessions this prompting would be faded so that the parent independently engages in these self-evaluation, planning and goal setting skills.

Praise use of specific self-regulatory skills. Descriptive praise can be powerful reinforcement (Allen, Hart, Buell, Harris, \& Wolf, 1964). When parents demonstrate the use of self-regulatory skills, practitioners can comment on what they've done, particularly if it's an emerging skill, 'I'm impressed that you were able to identify a few things that you did well and something specific you could improve. I didn't even have to prompt you to do so."

Provide guidance through the change process. As parents participate in a behavioural parenting intervention they are supported through a definite sequence in behaviour change. They are provided guidance in: (a) specifying the behaviours to be targeted for change and selecting a goal, (b) making observations about these target behaviours, (c) selecting parenting strategies and formulating a parenting plan, (d) reviewing progress and making adjustments to the plan as required, and finally (e) taking steps to ensure that desired changes are maintained. Over the course of a parenting intervention, there is often the opportunity for a number of target behaviours to be worked on in this manner. Thus the principle of sufficient exemplars is employed whereby the goal is for parents to have worked through a sufficient number of examples to facilitate the generalisation of this process (see Stokes \& Baer, 1977).

Apply the principles of the minimally sufficient intervention. Practitioners should tailor the level of support offered to parents over the course of an intervention. As the parent becomes proficient at encouraging themselves and linked-in to the natural reinforcers for using effective parenting and self-regulatory strategies, practitioners should decrease (or thin) their praise and encouragement. Attention and praise from the practitioner is not going to be 
available once the intervention finishes and it is important that the parent does not become dependent upon such reinforcement.

Use "signalled" fading of support. Sometimes as practitioners fade their prompts and thin their encouragement, the skills parents were displaying also disappear; practitioners stop prompting parents to evaluate how they went after practising a skill and the parents stop evaluating. A useful strategy to overcome this is to alert parents in advance that prompts and encouragement will be reduced, but that it is expected that they will continue to use the skills and ideas. Again, the use of rules in this fashion can lead to the maintenance of both selfregulatory and parenting strategies (Malott, 1988).

Ask parents to share their rationale for decisions. Asking parents to share their rationales for their decisions communicates that parents have options and control over their behaviour and, we suggest, strengthens all facets of self-regulation.

\section{Promoting Self-Regulation and Workforce Development}

Another potential application of self-regulation principles relates to the clinical supervision of practitioners (Sanders, McGee, Loureio, \& Murphy-Brennan, 2013). The successful translation into practice of evidence based interventions requires practitioners to be able to deliver interventions competently. Competent delivery of programs requires a workplace culture that values evidence based practices, organisational support from line management and access to supervision. Parenting interventions are delivered by a wide range of practitioners many of whom do not have a workplace culture of regular supervision. Even in disciplines that have such a culture, as in clinical psychology and social work, supervision is not always available and the traditional model of having an experienced and expert clinical supervisor available is rarely attained.

An alternative is the use of a peer support self-regulation approach to supervision. Sanders et al. (2013) described the Peer Assisted Supervision and Support (PASS) system 
that utilises self-regulation principles. In the PASS approach structured peer supervision sessions are conducted in small groups (4-5 practitioners) who are led by a rotational peer facilitator. Each practitioner is assigned on a rotational basis to be the leader and to structure the sessions. Each member of the group has to bring along a videotape or audiotape of an interview with a parent and be prepared to review the tape with the assistance of peers.

In undertaking PASS the practitioner whose tape is being reviewed previews the tape and then begins a formal process of self-evaluation and reflection. For example, "What were my goals?... What did I do well?... What should I do differently?... What are my practice goals for next time?..." At each stage of the process the peer facilitator prompts the practitioner to review their own performance then invites comments and suggestions from other group members to assist the practitioner identify future practice goals. This process parallels closely the process parents go through in individual coaching sessions with a therapist.

\section{Applying Self-Regulation to Organisations}

Self-regulation principles also have relevance to organisations providing parenting support. It is not uncommon for an organisation to lack coherence in its aims and practice, and to be managed in a "top-down" fashion with decisions regarding services being imposed on service delivery staff being made in the absence of consultation, input or ownership by those staff. This can increase resistance to policy decisions (Webster-Stratton \& Taylor, 1998). A lack of consultation between staff and management can also result in logistical barriers to service provision going unresolved. Further, often there are no mechanisms in place to feedback outcomes being achieved with families. This can lead to a continuation of services that are not demonstrably effective and management to rely on organisational "spin" to satisfy consumer, political and media demands for accountability. 
In contrast, organisations adopting self-regulation principles have a clear mission in supporting procedural guidelines and performance targets that are collaboratively determined with staff. Mechanisms are in place to collect output and outcome data and measures of program fidelity. Reviews of performance targets are undertaken on a routine and regular basis to inform training and support efforts and to inform decision making at a policy level. Staff accomplishments in delivering services are recognised and celebrated and, if necessary, management assist staff to identify and overcome barriers to the implementation of services. These organisations support staff by ensuring access to adequate training, supervision and resources, providing strategies and materials for service promotion (e.g., brochures, posters and press releases). Organisational management take action to support the financial, organisational and human resources required to support the work of practitioners. These organisations are also likely to be proactive in seeking to influence the future development of programs in which they have invested. Organisations might provide feedback to program developers and researchers regarding implementation successes and difficulties, and how programs could be developed to better meet the needs of specific client groups.

Collaboration with research groups to examine field-generated questions are typically encouraged (Fixsen et al., 2005, 2009; Sanders \& Turner, 2005).

Programs or new innovations may not be adopted if there is a lack of congruence between its theory or practical implementation and the orientation and practices of an organisation (Backer, Liberman, \& Kuehnel, 1986; Sanders, Prinz, \& Shapiro, 2009). Consequently, the dissemination of empirically supported parenting programs must not only involve adequately training practitioners in the content and processes of an intervention, it must also engage participating organisations to ensure that the accurate delivery of the intervention is supported.

\section{Promoting Self-regulation via Parenting Interventions: Advantages and Opportunities}


There is evidence that self-regulatory capacity as measured in early childhood predicts a wide variety of indices of social competence and wellbeing in adolescence and adulthood (e.g., Mischel et al., 1988; Moffitt et al., 2011; Shoda et al., 1990; Tremblay et al., 1995). This, combined with the absence of any evidence that one can have too much selfregulatory capacity (Grant \& Schwartz, 2011), has implications for policy-makers who seek to enhance the physical, mental and financial health of the population and reduce the crime rate. Large-scale or universal interventions aimed at enhancing self-regulation may improve the welfare of the entire population and reduce a range of problems that burden modern society.

While a range of psychological and behaviour change interventions increase participants' self-regulatory skills, there may be advantages to building self-regulatory capacity through a parenting intervention. Parenting interventions can be made universally available, making participation normative and increasing the likelihood that large portions of the population will be reached (Sanders et al., 2008; Prinz, Sanders, Shapiro, Whitaker, \& Lutzker, 2009). Developmentally, these interventions can target children during critical periods of their development such as the early childhood period and adolescence when they are most likely to have a beneficial impact (Knudsen, Heckman, Cameron, \& Shonkoff, 2006; Smart et al., 2005). Further, the costs of establishing the infrastructure to implement a public health parenting intervention are modest and substantially less than the amount of government expenditure it would save (Foster, Prinz, Sanders, \& Shapiro, 2008; Mihalopoulos, Sanders, Turner, Murphy-Brennan, \& Carter, 2007).

The benefits of parenting interventions may also extend beyond children who have more adaptive skills and less problem behaviour. For reasons discussed earlier parenting interventions may enhance parent's self-regulatory capacity and, as a result, lead parents to reap additional benefits. Parents who participate in parenting programs typically report fewer 
personal adjustment problems and higher relationship satisfaction (e.g., Dadds, Schwartz, \& Sanders, 1987; Sanders \& McFarland, 2000; Zubrick et al., 2005). We have also observed apparent cascading effects such that some parents generalise their self-regulatory skills to other life domains. For instance one parent, as she neared completion of a parenting program, demonstrated enhanced interpersonal skills with adults by making an appointment with her child's teacher at school and raising concerns regarding bullying in a clear and nonescalatory fashion. Another parent, after achieving improvements in his child's behaviour, brainstormed and followed through on solutions to a number of obstacles that had previously prevented him from obtaining employment.

The potential of parenting interventions to have a range of collateral benefits for parents and families suggests a whole new research agenda. How far reaching are the benefits of parenting interventions? What strategies might be further incorporated within a parenting intervention to enhance these benefits? How can we best assess self-regulatory capacity and evidence of collateral benefits in a parenting context?

\section{Efficacy of a Self-Regulation Approach to Parenting}

The early demonstration of the role of the self-regulation approach to parenting was reported in the early eighties by Sanders and Glynn (1981). They trained five parents of preschoolers with disruptive behaviour problems to modify their own behaviour through the use of self-regulation skills (goal setting, self-monitoring, monitoring of implementation of a parenting plan to enable self-evaluation). When parents were taught self-management skills they were more likely to generalise their skills to untrained childcare situations than when they simply received instruction and feedback. This early study was a foundation study for the development of the Triple P-Positive Parenting Program which is a tiered multilevel system of parenting intervention using a self-regulation approach within a public health model of intervention. A large number of studies have attested to the efficacy of this 
approach to working with parents and several independent meta-analyses have been

published demonstrating positive child and parent outcomes (see Nowak \& Heinrichs, 2008).

More recently the self-regulation approach has been successfully applied to media and technology assisted approaches to parenting. For example, Sanders, Baker, and Turner (2012) recently evaluated the effects of an eight-session Online-version of Triple $\mathrm{P}$ that employed a self-regulation approach and demonstrated a significantly greater sustained improvement in the Online conditions compared to controls on measures of conduct problems, parenting selfefficacy, dysfunctional parenting and parental anger. The same process of promoting selfregulation can also be employed in running parenting groups, individually administered therapy, parenting interventions delivered over the phone and through self-help text based interventions.

\section{Future Directions}

Although the clinical methods for delivering parenting interventions using a selfregulation framework have been well articulated in practitioner manuals (e.g., Sanders, Turner, \& Markie-Dadds, 1998), there continues to be a gap in how to best measure selfregulation processes. Although measures of task specific parental and practitioner selfefficacy have been developed and validated and shown to be sensitive to the effects of intervention (e.g., Sanders \& Woolley, 2005; Turner and Sanders, 1999 cited in Sanders, Murphy-Brennan, \& McAuliffe, 2003), it is only recently that measures of other aspects of the self-regulation approach articulated here have begun to be developed (e.g., Hamilton, Matthews, \& Crawford, 2012) and these are yet to be demonstrated to be valid and sensitive in an intervention context. Table 2 summarises a number of self-regulation measures to assess self-regulation competence of children, parents and parenting practitioners. Selfregulation measures are required to assess the occurrence of competencies used as part of a method of producing behaviour change and an explanation for that change. Do practitioner 
strategies that theoretically should promote parental self-regulation (e.g., prompting of parental goal setting) actually do so, and does change in self-regulatory capacity mediate changes in desired parenting and/or child outcomes? Research is needed to develop sound measures of the components of self-regulation processes (e.g., goal setting, self-evaluation, self-monitoring).

\section{Conclusions}

Self-regulation predicts future health, wealth, and social behaviour. Enhancing selfregulation at a population level is likely to benefit society by improving citizens' health and wealth and reducing a range of societal problems. Parenting programs based on cognitivebehavioural and social learning principles would seem to represent a viable way of achieving these goals. They have been demonstrated to be capable of promoting positive health and developmental outcomes in children, capable of being disseminated at a universal level, and with a desirable cost-benefit ratio.

Parents who have strong self-regulatory capacity and who use positive parenting practices are likely to benefit their children by promoting their children's self-regulation skills. We have argued that the integration of a self-regulation perspective into parenting interventions is a powerful method of training parents to change their parenting practices. The approach enables parents to become less reliant on others to produce and maintain change. Further, it is argued that self-regulatory principles are robust and apply to all other participants of the parent consultation process including service providers, managers, program disseminators, program developers and researchers.

A self-regulation perspective to parenting has a range of implications for practice and leads to a number of predictions that are yet to be empirically tested. However, in order to test these predictions sound measures of the components of self-regulation processes need to be developed. 


\section{References}

Allen, K. E., Hart, B. M., Buell, J. S., Harris, F. R., \& Wolf, M. M. (1964). Effects of social reinforcement on isolate behavior of a nursery school child. Child Development, 35 , $511-518$

Anderson, P. (2002). Assessment and development of executive function (EF) during childhood. Child Neuropsychology, 8, 71-82.

Avakame, E. F. (1998). Intergenerational transmission of violence, self-control, and conjugal violence: A comparative analysis of physical violence and psychological aggression. Violence and Victims, 13, 301-316.

Backer, T. E., Liberman, R. P., \& Kuehnel, T. G. (1986). Dissemination and adoption of innovative psychosocial interventions. Journal of Consulting and Clinical Psychology, $54,111-118$.

Bandura, A. (1977a). Self-efficacy: Toward a unifying theory of behavioral change. Psychological Review, 84, 191-215.

Bandura, A. (1977b). Social learning theory. Englewood Cliffs, NJ: Prentice-Hall.

Bandura, A. (1986). Social foundations of thought and action: A social cognitive theory. Englewood Cliffs, NJ: Prentice Hall.

Bandura, A. (1991). Social cognitive theory of moral thought and action. In W. M. Kurtines \& J. L. Gewirtz (Eds.), Handbook of moral behavior and development (Vol. 1, pp. 45103). Hillsdale, NJ: Lawrence Erlbaum.

Bandura, A. (1994). Self-efficacy. In V. S. Ramachaudran (Ed.), Encyclopedia of human behavior (Vol. 4, pp. 71-81). New York, NY: Academic Press.

Barlow, D. H., Allen, L. B., \& Choate, M. L. (2004). Toward a unified treatment of emotional disorders. Behavior Therapy, 35, 205-230.

Baumeister, R. F., Heatherton T. F., \& Tice, D. M. (1994). Losing control: How and why 
people fail at self-regulation. San Diego, CA: Academic Press.

Bouchard, T. J., Jr. (2004). Genetic influence on human psychological traits: A survey. Current Directions in Psychological Science, 13, 148-151.

Campis, L., Lyman, R. D., \& Prentice-Dunn, S. (1986). The parental locus of control scale: Development and validation. Journal of Clinical Child Psychology, 15, 260-267.

Carver, C. S., \& Scheier, M. F. (2011). Self-regulation of action and affect. In K. D. Vohs \& R. F. Baumeister (Eds.) Handbook of self-regulation: Research, theory, and applications (2 $2^{\text {nd }}$ ed., pp. 3-21). New York, NY: Guilford Press.

Chan, R. C. K., Shum, D., Toulopoulou, T., \& Chen, E. Y. H. (2008). Assessment of executive functions: Review of instruments and identification of critical issues. Archives of Clinical Neuropsychology, 23, 201-216.

Coleman, P. K., \& Karraker, K. H. (2000). Parenting self-efficacy among mothers of schoolage children: Conceptualisation, measurement, and correlates. Family relations, 49, $13-24$.

Csikszentmihalyi, M. (1990). Flow: The psychology of optimal experience. New York, NY: Harper Perennial.

Dadds, M. R., Schwartz, S. \& Sanders, M. R. (1987). Marital discord and treatment outcome in the treatment of childhood conduct disorders. Journal of Consulting and Clinical Psychology, 55, 396-403.

De Luca, C. R., \& Leventer, R. J. (2008). Developmental trajectories of executive functions across the lifespan. In V. Anderson \& P. J. Anderson (Eds.) Executive functions and frontal lobes: A lifespan perspective (pp. 23-56). Philadelphia, PA: Taylor and Francis.

Duckworth, A. L., \& Seligman, M. E. P. (2005). Self-discipline outdoes IQ in predicting academic performance of adolescents. Psychological Science, 16, 939-944.

Dumka, L. E., Stoerzinger, H. D., Jackson, K. M., \& Roosa, M. W. (1996). Examination of 
the cross-cultural and cross-language equivalence of the parenting self-agency measure. Family Relations, 45, 216-222.

Ebstein, R. P. (2006). The molecular genetic architecture of human personality: Beyond selfreport questionnaires. Molecular Psychiatry, 11, 427-445.

Eisenberg, N. (2004). Prosocial and moral development in the family. In T. A. Thorkildsen \& H. J. Walberg (Eds.) Nurturing morality (pp. 119-135). New York, NY: Kluwer Academic/Plenum Publishers.

Finkenauer, C., Engels, R. C. M. E., \& Baumeister, R. F. (2005). Parenting behaviour and adolescent behavioural and emotional problems: The role of self-control. International Journal of Behavioral Development, 29, 58-69.

Fixsen, D. L., Blase, K. A., Naoom, S. F., \& Wallace, F. (2009). Core implementation components. Research on Social Work Practice, 19, 531-540.

Fixsen, D. L., Naoom, S. F., Blase, K. A., Friedman, R. M., \& Wallace, F. (2005). Implementation research: A synthesis of the literature. Tampa, FL: University of South Florida, Louis de la Parte Florida Mental Health Institute, The National Implementation Research Network.

Foster, E. M., Prinz, R. J., Sanders, M. R., \& Shapiro, C. J. (2008). The costs of a public health infrastructure for delivering parenting and family support. Children and Youth Services Review, 30, 493-501.

Gioia, G. A., Isquith, P. K., Guy, S. C., \& Kenworthy, L. (2000). Behavior Rating Inventory of Executive Function. Child Neuropsychology, 6, 235-238.

Gioia, G. A., Isquith, P. K., Kenworthy, L., \& Barton, R. M. (2002). Profiles of everyday executive function in acquired developmental disorders. Child Neuropsychology, 8 , 121-137.

Gollwitzer, P. M. (1999). Implementation intentions: Strong effects of simple plans. 
American Psychologist, 54, 493-503.

Grant, A. M., \& Schwartz, B. (2011). Too much of a good thing: The challenge and opportunity of the inverted U. Perspectives on Psychological Science, 6, 61-76.

Guimond, A. B., Wilcox, M. J., \& Lamorey, S. G. (2008). The early intervention parenting self-efficacy scale (EIPSES): Scale construction and initial psychometric evidence. Journal of Early Intervention, 30, 295-320.

Hamilton, V. E., Matthews, J. M., \& Crawford, S. B. (2012). Development and preliminary validation of a parenting self-regulation scale: "Me as a Parent." Manuscript submitted for publication.

Hayes, S. C., Strosahl, K. D., \& Wilson, K. G. (1999). Acceptance and commitment therapy: An experiential approach to behavior change. New York, NY: Guilford.

Johnston, C. \& Mash, E. J. (1989) A measure of parenting satisfaction and efficacy. Journal of Clinical Child Psychology, 18, 167-175.

Karoly, P. (1993). Mechanisms of self-regulation: A systems view. Annual Review of Psychology, 44, 23-52.

Karreman, A., van Tuijl, C., van Aken, M. A. G., \& Dekovic, M. (2008). Parenting, coparenting, and effortful control in preschoolers. Journal of Family Psychology, 22, $30-40$.

Kashdan, T. B., \& Rottenberg, J. (2010). Psychological flexibility as a fundamental aspect of health. Clinical Psychology Review, 30, 467-480.

Kendall, P. C., \& Braswell, L. (1985). Cognitive-behavioral therapy for impulsive children. New York, NY: Guilford.

Kendall, P. C., \& Wilcox, L. E. (1979). Self-control in children: Development of a rating scale. Journal of Consulting and Clinical Psychology, 47, 1020-1029.

Kendall, P. C., \& Wilcox, L. E. (1980). Cognitive-behavioral treatment for impulsivity: 
Concrete versus conceptual training in non-self-controlled problem children. Journal of Consulting and Clinical Psychology, 48, 80-9 1.

Kendall, P. C., \& Zupan, B. A. (1981). Individual versus group application of cognitivebehavioral self-control procedures with children. Behavior Therapy, 12, 344-359.

Knudsen, E. I., Heckman, J. J., Cameron, J. L., \& Shonkoff, J. P. (2006). Economic, neurobiological, and behvioral perspectives on building America's future workforce. Proceedings of the National Academy of Sciences of the United States of America, 103, 10155-10162.

Koole, S. L., van Dillen, L. F., \& Sheppes, G. (2011). The self-regulation of emotion. In K. D. Vohs \& R. F. Baumeister (Eds.) Handbook of self-regulation: Research, theory, and applications ( $2^{\text {nd }}$ ed., pp. 22-40). New York, NY: Guilford Press.

Kopp, C. B. (1982). Antecedents of self-regulation: A developmental perspective. Developmental Psychology, 18, 199-214.

Linehan, M. M. (1993). Cognitive-behavioral treatment of borderline personality disorder. New York, NY: Guilford Press.

Malott, R. (1988). Rule-governed behavior and behavioral anthropology. The Behavior Analyst, 11, 181-203.

Martell, C. R., Addis, M. E. \& Jacobson, N. S. (2001). Depression in context: Strategies for guided action. New York, NY: Norton

Martell, C. R., Dimidjian, S., \& Herman-Dunn, R. (2010). Behavioral activation for depression: A clincian's guide. New York, NY: Guilford

Mazzucchelli, T. G., Kane, R. T., \& Rees, C. S. (2010). Behavioral activation interventions for well-being: A meta-analysis. The Journal of Positive Psychology, 5, 105-121. 
Mezo, P. G. (2009). The Self-Control and Self-Management Scale (SCMS): Development of an adaptive self-regulatory coping skills instrument. Journal of Psychopathology and Behavioral Assessment, 31, 83-93.

Mihalopoulos, C., Sanders, M. R., Turner, K. M. T., Murphy- Brennan, M., \& Carter, R. (2007). Does the Triple P-Positive Parenting Program provide value for money? Australian and New Zealand Journal of Psychiatry, 41, 239-246.

Mischel, W., Shoda, Y., \& Peake, P. K. (1988). The nature of adolescent competencies predicted by preschool delay of gratification. Journal of Personality and Social Psychology, 54, 687-696.

Moffitt, T. E., Arseneault, L., Belsky, D., Dickson, N., Hancox, R. J., Harrington, H.,... Caspi, A. (2011). A gradient of childhood self-control predicts health, wealth, and public safety. Proceedings of the National Academy of Sciences of the United States of America, 108, 2693-2698.

Muraven, M., Baumeister, R. F., \& Tice, D. M. (1999). Longitudinal improvement of selfregulation through practice: Building self-control strength through repeated exercise. The Journal of Social Psychology, 139, 446-457.

Nezu, A. M. (1986). Efficacy of a social problem-solving therapy approach for unipolar depression. Journal of Consulting and Clinical Psychology, 54, 196-202.

Nowak, C., \& Heinrichs, N. (2008). A comprehensive meta-analysis of Triple P-Positive Parenting Program using hierarchical linear modeling: Effectiveness and moderating variables. Clinical Child and Family Psychology Review, 11, 114-144.

Papies, E. K., \& Aarts, H. (2011). Nonconscious self-regulation, or the automatic pilot of human behavior. In K. D. Vohs \& R. F. Baumeister (Eds.) Handbook of selfregulation: Research, theory, and applications $\left(2^{\text {nd }}\right.$ ed., pp. 125-142). New York, NY: Guilford Press. 
Patterson, G. R., \& Chamberlain, P. (1994). A functional analysis of resistance during parent training therapy. Clinical Psychology: Science and Practice, 1, 53-70.

Prinz, R. J., Sanders, M. R., Shapiro, C. J., Whitaker, D. J. \& Lutzker, J. R. (2009). Population-based prevention of child maltreatment: The US Triple P system population trial. Prevention Science, 10, 1-12.

Rehm, L. P. (1977). A self-control model of depression. Behavior Therapy, 8, 787-804.

Robin, A. L., Fischel, J. E., Brown, K. E. (1984). The measurement of self-control in children: Validation of the Self-control Rating Scale. Journal of Pediatric Psychology, 9, $165-175$.

Rohrbeck, C. A., Azar, S. T., \& Wagner, P. E. (1991). Child Self-Control Rating Scale: Validation of a child self-report measure. Journal of Clinical Child Psychology, 20, 179-183.

Sanders, M. R. (1998). The empirical status of psychological interventions with families of children and adolescents. In L. L'Abate (Ed.), Family psychopathology: The relational roots of dysfunctional behavior (pp. 427-465). New York, NY: Guilford Press.

Sanders, M. R. (1999). Triple P-Positive Parenting Program: Towards an empirically validated multilevel parenting and family support strategy for the prevention of behavior and emotional problems in children. Clinical Child and Family Psychology Review, 2, 71-90.

Sanders, M. R. (2008). Triple P-Positive Parenting Program as a public health approach to strengthening parenting. Journal of Family Psychology, 22, 506-517.

Sanders, M. R., Baker, S., \& Turner, K. M. T. (2012). A randomized controlled trial evaluating the efficacy of Triple P Online with parents of children with early onset conduct problems. Behaviour Research and Therapy, 50, 675-684.

Sanders, M. R., \& Glynn, E. L. (1981). Training parents in behavioral self-management: An 
analysis of generalization and maintenance effects. Journal of Applied Behavior Analysis, 14, 223-237.

Sanders M. R., \& Lawton, J. (1993). Discussing assessment findings with families: The guided participation model of information transfer. Child and Family Behavior Therapy, $15,5-35$.

Sanders, M. R., Mazzucchelli, T. G., \& Ralph, A. (2012). Promoting parenting competence through a self-regulation approach to feedback. In R. M. Sutton, M. J. Hornsey, \& K. M. Douglas (Eds.) Feedback: The communication of praise, criticism, and advice (pp. 305-321). New York, NY: Peter Lang.

Sanders, M. R., \& McFarland, M. (2000). Treatment of depressed mothers with disruptive children: A controlled evaluation of cognitive behavioral family intervention. Behavior Therapy, 31, 89-112.

Sanders, M.R., McGee, E., Loureiro, T., \& Murphy, M. (2013). Peer-Assisted Supervision and Support (PASS): Peer support and self-regulation training to promote effective implementation of evidence-based parenting interventions. Manuscript in preparation.

Sanders, M. R., Murphy-Brennan, M., \& McAuliffe, C. (2003). The development, evaluation and dissemination of a training program for general practitioners in evidence-based parent consultation skills. International Journal of Mental Health Promotion, 5(4), $13-$ 20.

Sanders, M. R., Prinz, R. J., \& Shapiro, C. J. (2009). Predicting utilization of evidence-based parenting interventions with organizational, service-provider and client variables. Administration and Policy in Mental Health and Mental Health Services Research, 36, 133-143.

Sanders, M.R., Ralph, A., Sofronoff, K., Gardiner, P., Thompson, R., Dwyer, S., \& Bidwell, K. (2008). Every Family: A population approach to reducing behavioral and emotional 
problems in children making the transition to school. Journal of Primary Prevention, 29, 197-222.

Sanders, M. R., \& Turner, K. M. T. (2005). Reflections on the challenges of effective dissemination of behavioural family intervention: Our experience with the Triple $\mathrm{P}-$ Positive Parenting Program. Child and Adolescent Mental Health, 10, 158-169.

Sanders, M. R., Turner, K. M. T., \& Markie-Dadds, C. (1998). Practitioner's manual for enhanced Triple P. Brisbane, Australia: Families International Publishing.

Sanders, M. R., \& Woolley, M. L. (2005). The relationship between maternal self-efficacy and parenting practices: Implications for parent training. Child: Care, Health and Development, 31, 65-73.

Senn, T. E., Espy, K. A., \& Kaufmann, P. M. (2004). Using path analysis to understand executive function organization in preschool children. Developmental Neuropsychology, 26, 445-464.

Shoda, Y., Mischel, W., \& Peake, P. K. (1990). Predicting adolescent cognitive and selfregulatory competencies from preschool delay of gratification: Identifying diagnostic conditions. Developmental Psychology, 26, 978-986.

Smart, D., Richardson, N., Sanson, A., Dussuyer, I., Marshall, B., Toumbourou, J. W.,... Oberklaid, F. (2005). Patterns and precursors to adolescent antisocial behaviour: Outcomes and connections. Melbourne, Australia: Australian Institute of Family Studies.

Stokes, T. F., \& Baer, D. M. (1977). An implicit technology of generalization. Journal of Tangney, J. P., Baumeister, R. F., \& Boone, A. L. (2004). High self-control predicts good adjustment, less pathology, better grades, and interpersonal success. Journal of Personality, 72, 271-322.

Tangney, J. P., Baumeister, R. F., \& Boone, A. (2004). High self-control predicts good 
adjustment, less pathology, better grades, and interpersonal success. Journal of Personality, 72, 271-324.

Tremblay, R. E., Boulerice, B., Arseneault, L., \& Niscale, M. J. (1995). Does low self-control during childhood explain the association between delinquency and accidents in early adolescence? Criminal Behaviour and Mental Health, 5, 439-451.

Tsukayama, E., Toomey, S. L., Faith, M. S., \& Duckworth, A. L. (2010). Self-control as a protective factor against overweight status in the transition from childhood to adolescence. Archives of Pediatrics and Adolescent Medicine, 164, 631-635.

Valiente, C., Lemery-Chalfant, K., \& Reiser, M. (2007). Pathways to problem behaviors: Chaotic homes, parent and child effortful control, and parenting. Social Development, 16, 249-267.

Webster-Stratton, C. (1998). Preventing conduct problems in head start children: Strengthening parenting competencies. Journal of Consulting and Clinical Psychology, $66,715-730$.

Webster-Stratton, C., \& Taylor, T. K. (1998). Adopting and implementing empirically supported interventions: A recipe for success. In A. Buchanan \& B. L. Hudson (Eds.), Parenting, schooling and children's behaviour: Interdisciplinary approaches (pp. 127160). Aldershot, England: Ashgate.

Zubrick, S. R., Ward, K., Silburn, S. R., Lawrence, D., Williams, A. A., Blair, E.,... Sanders, M. R. (2005). Prevention of child behavior problems through universal implementation of a group behavioral family intervention. Prevention Science, 6, 287-304. 


\section{Author Note}

Correspondence concerning this article should be addressed to Matthew R. Sanders,

Parenting and Family Support Centre, University of Queensland, Brisbane, Queensland 4072, Australia. E-mail: m.sanders@psy.uq.edu.au. 
Table 1

Parenting Practices and the Development of Self-Regulation in Children

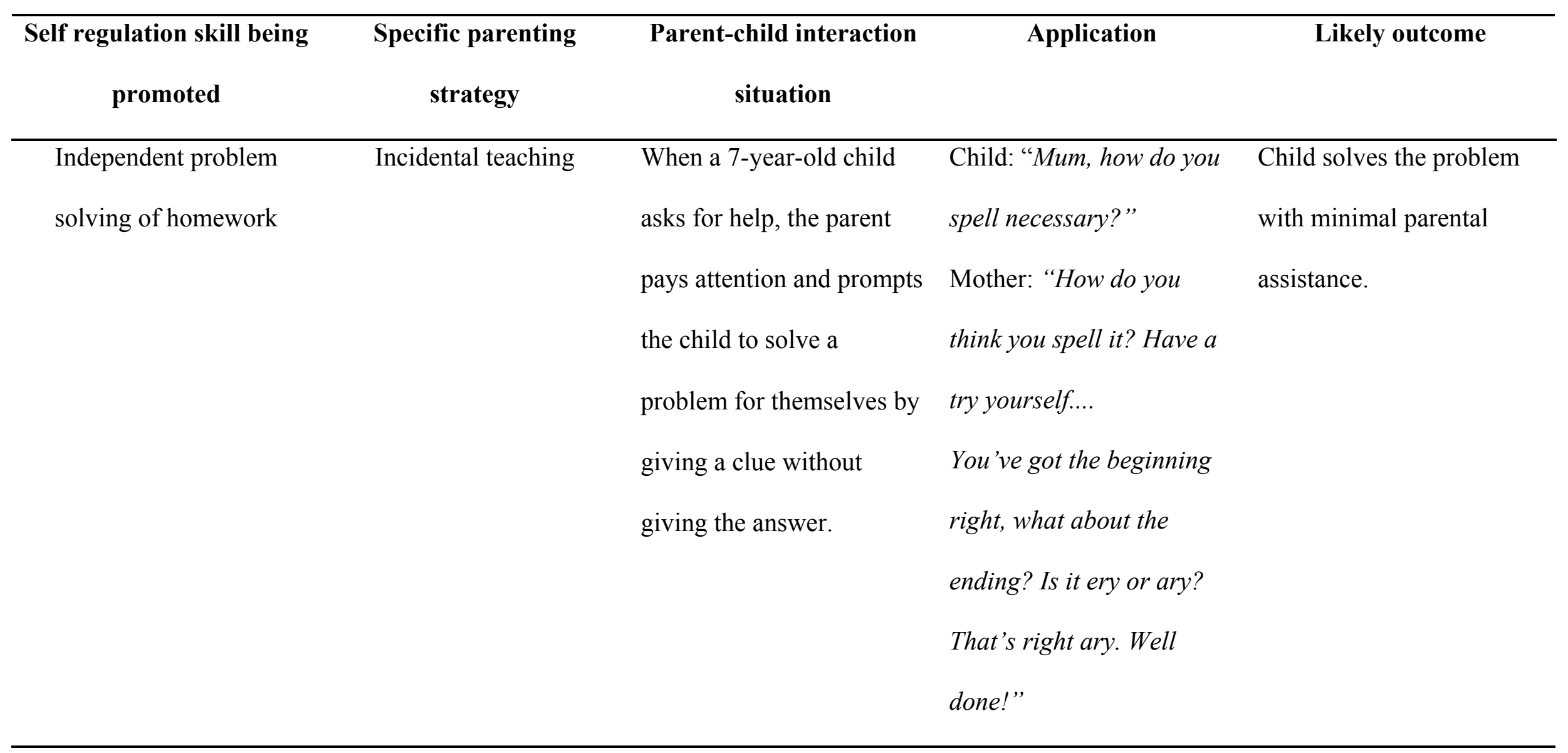


Independent brushing of

teeth
Ask-Say-Do
Parent initiates an

interaction to teach a child

to brush their teeth and

uses the least intrusive

prompt needed to help the

child execute the task
Mother: "What's the first

thing you do when you

brush your teeth?"

Child: "I don't know."

Mother: "Well you get

your toothbrush and

squeeze some toothpaste

on the brush. Can you do

that?"

Child: "No. I can't do it."

Mother: "Having trouble

are you? I squeeze the

paste up here" (using

manual guidance prompt,
Child more likely to try again in the future 
with parent hand over

child's hand). “That's

right. Well done."

\begin{tabular}{|c|c|c|c|c|}
\hline Emotion regulation & $\begin{array}{l}\text { Positive attending to } \\
\text { child's attempts to regulate } \\
\text { emotion }\end{array}$ & $\begin{array}{l}\text { Parent provides positive } \\
\text { attention following a child } \\
\text { showing restraint in a } \\
\text { situation of provocation } \\
\text { from sibling. }\end{array}$ & $\begin{array}{l}\text { "James, I really like the } \\
\text { way you ignored Aaron } \\
\text { when he was teasing you } \\
\text { just then." }\end{array}$ & $\begin{array}{l}\text { Child learns to develop a } \\
\text { plan to deal with other } \\
\text { children who are annoying } \\
\text { or irritating. }\end{array}$ \\
\hline $\begin{array}{l}\text { Self monitoring of own } \\
\text { behaviour }\end{array}$ & $\begin{array}{l}\text { Prompting the child to } \\
\text { review or reflect on own } \\
\text { performance or } \\
\text { achievement }\end{array}$ & $\begin{array}{l}\text { Parent asks child to review } \\
\text { and report on how they } \\
\text { have been going with the } \\
\text { practice of a skill or a } \\
\text { behaviour }\end{array}$ & $\begin{array}{l}\text { Parent: "How many } \\
\text { stickers have you got on } \\
\text { your chart now?" or "Tell } \\
\text { me what you have done to } \\
\text { get all those stickers." }\end{array}$ & $\begin{array}{l}\text { Child learns to track and } \\
\text { report on their own } \\
\text { behaviour. }\end{array}$ \\
\hline $\begin{array}{l}\text { Self evaluation of } \\
\text { accomplishments }\end{array}$ & $\begin{array}{l}\text { Asking child to describe } \\
\text { their accomplishment }\end{array}$ & show them a painting they & $\begin{array}{l}\text { Parent: "Well now, that } \\
\text { does look like an }\end{array}$ & $\begin{array}{l}\text { Child learns to describe } \\
\text { their own }\end{array}$ \\
\hline
\end{tabular}


while listening carefully to have just completed. child's statements interesting painting. Tell

be about it.... What about

this part up here?" accomplishments and self-

evaluate what they have

accomplished. Becomes

less reliant on praise or

attention.

\begin{tabular}{|c|c|c|c|c|}
\hline Creating a positive & Parent asks child to talk & After a discussion with a & Parent: "Do you think you & Child anticipates they can \\
\hline \multirow{5}{*}{ expectancy for change } & & parent conveys their & Child: "I think so." & \\
\hline & & confidence in the child's & Parent: "I agree with you, & \\
\hline & & capacity to deal with the & I think you really can do it. & \\
\hline & & situation. & Sounds like it's sure worth & \\
\hline & & & a try." & \\
\hline
\end{tabular}


Table 2

Measures of Child and Parent Self-Regulation

\begin{tabular}{cccc}
\hline Name and primary & Description & Norms & Validity \\
reference & & \\
\hline
\end{tabular}

Child Measures

Self-Control Rating Scale

(SCRS)

Kendall \& Wilcox

(1979) 33-item teacher and parent In the original study, rating scale to assess self-

norms were reported for

control in children based

110 typically developing

on a cognitive-behavioural

$3^{\text {rd }}$ - through $6^{\text {th }}$-graders.

definition of self-control.
The SCRS has high

internal consistency $(\alpha=$

.98). The SCRS also has

high test-retest reliability

of .84 over a three to four

week period.

\section{The SCRS correlated}

significantly with

behavioural observations,

has been found to be

sensitive to changes

produced by cognitive-

behavioural self-control

training programs (Kendall

\& Wilcox, 1980; Kendall

\& Zupan, 1981), and

differentiate among patient 
populations (Robin,

Fischel, \& Brown, 1984).

The correlation between

teacher and parents'

ratings was .66 (Kendall \&

Braswell, 1982).

Child Self-Control Rating Scale (CSCRS)

Rohrbeck, Azar, \&

Wagner (1991)

Behavior Rating Inventory

of Executive Function

\section{3-item self-report scale} modelled after the SCRS.

studied with 103 typically

developing $3^{\text {rd }}$ - and $5^{\text {th }}$ -

grade students.

$(\alpha=.90)$ and 6- to 8-week

test-retest reliability $(r=$

$.84)$.

Internal-External Locus of

Control Scale for

Children.

86 item teacher and parent rating scale designed to
The BRIEF Parent Form

has been studied with 1419
Satisfactory consistency

$(\alpha=.80$ to .98$)$ and 2-

\section{The BRIEF correlates}

significantly with other 
Gioia, Isquith, Guy, executive functioning.

\& Kenworthy (2000) The measure comprises eight empirically derived scales and three broad indexes. children and adolescents

aged between 5 and 18

years. The BRIEF

Teacher Form has been

studied with a similar

sample of 720 children and week test-retest reliability

$(r=.79$ to .88$)$.$$
(r=.79 \text { to. }
$$

index adolescents. measures of emotional and behavioural functioning such as the Attention

Problem scale on the Child Behavior Checklist and items assessing inattention and hyperactivityimpulsivity on the $A D H D$ Rating Scale IV. The BRIEF has also been shown to discriminate between children with a range of developmental disorders (Gioia, Isquith, Kenworthy, \& Barton, 2002). 
General Adult Measures

\section{Self-Control Scale (SCS)}

Tangney, Baumeister, and Boone (2004)

Self-Control and Self-

Management Scale

(SCMS) 36-item instrument

designed to assess trait

self-control. It samples

controlling thoughts,

feelings, impulses, and

performances, as well as

breaking bad habits. A 13-

item short form has also

been developed.

16-item instrument

designed to assess trait

self-control and self-

The SCS has been studied

with two undergraduate

student samples $(n=351$

and $n=255$ ).

The SCMS has been

studied with a multiethnic

student sample $(n=302)$.
High internal consistency

$(\alpha=.89$ and .83 to .85 for

the long and short forms

respectively) and 3-week

test-retest reliability $(r=$

.89 and .87 for the long

and short form

respectively).

evaluation, self-reinforcing

and total scales all show
Higher scores on SCS

correlated with higher

grade point average, better

adjustment (fewer reports

of psychopathology,

higher self-esteem), less

binge eating and alcohol

abuse, better relationships

and interpersonal skills,

secure attachment, and

more optimal emotional

responses.

The SCMS obtained

significant moderate to

high correlations with 
Mezo (2009)

management skills. Three

dimensions are

measured—self-

monitoring, self-

evaluation, and self-

reinforcing

The PSOC was originally

used with parents of

infants, but was

subsequently studied with a sample of 297 mothers

and 215 fathers of 4- to 9-
78 , and .81 respectively).

The SCMS has a 2-week

test-retest correlation of

.75.

satisfactory internal

other measures of self-

consistency $(\alpha=.74, .75, \quad$ control and psychological

distress. The SCMS did

not correlate significantly

with any of the

discriminant constructs

(social desirability, moral

beliefs, religious beliefs,

irrational beliefs).

The satisfaction, efficacy, Significant inverse

and total scales all show relationships were found

satisfactory internal

between PSOC and

consistency $(\alpha=.75, .76, \quad$ perceptions of child

and .79 respectively). Six- behavior problems. For

week test-retest

mothers, reported child

Mash, 1989) 
year old boys and girls.

\section{Parental Locus of Control} Scale (PLOC)

Campis, Lyman, \&

Prentice-Dunn

(1986) 47-item scale designed to

assess parental locus of

control. Five subscales

comprise the PLOC:

parental efficacy, parental

responsibility, child

control, fate/chance,

parental control.

\section{The PLOC was originally}

used with 105 parents of

elementary school-age

children-60 parents who

did not report experiencing

any difficulties in the

parenting role and 45

parents who had requested

services for parenting

problems. and for the total score ranged from .46 to .82 .

behavior problems related

to parenting satisfaction.

For fathers, child behavior

problems related both to

satisfaction and efficacy as

a parent.

Alpha coefficients for the Correlations between the

individual subscales were five PLOC subscales and

.79 (Parental

the validation measures

Responsibility), .66 (Child suggest that people with

Control), .70

(Fate/Chance), .71

external parental locus of

control orientation had low

Parental Control), and .44 self-efficacy accompanied

(Parental Efficacy). by frustration and a sense

of being dominated by

their child's demands. 
Also, less commitment to occupation and a general

belief in fate and chance as determinants of life events.

Three of the PLOC

subscales discriminated

between the theoretically

different groups of parents.

Parenting Self-Agency

Measure (PSAM)

Dumka, Stoerzinger,

Jackson, \& Roosa

(1996) 5-item measure of

parenting self-agency,

efined as parents' overall

confidence in their ability

to act successfully in the

parental role.
The PSAM has been

studied with a sample of

English speaking, middle-

income, Anglo mothers ( $n$

=90) and Spanish

speaking, low-income,

Mexican immigrant

mothers $(n=94)$.
Scale alpha coefficients

for the Anglo and Mexican

immigrant groups were .70

and .68 respectively.

active coping and

parenting acceptance,

negatively related to

parenting inconsistent

discipline, and not related 
to acceptance coping. For the Mexican immigrant group, PSAM was

positively related to positive reinterpretation coping and parenting acceptance and not related to acceptance coping.

Results also confirmed the functional and scalar equivalence for these two cultural groups.

Self-Efficacy in Parenting

Tasks Index (SEPTI)

Coleman \& Karraker (2000) 36-item scale designed to assess domain specific

self-efficacy in parents of elementary school age
The SEPTI has been studied with 145 mothers

of 5- to 12-year-old

children.
The achievement,

recreation, discipline,

nurturance, health and full-

scales all showed
The SEPTI total and

parent-outcome

converged with other 
children. Five subscales

comprise the SEPTI:

facilitating child's

achievement in school,

supporting child's need for

recreation including

socializing with peers,

provision of structure and

discipline, provision of

emotional nurturance, and

maintenance of child's

physical health.

Parenting Tasks Checklist

(PTC)

Sanders \& Woolley

\section{8-item checklist designed} to assess parents' taskspecific self-efficacy.

Two dimensions are satisfactory internal consistency $(\alpha=.74, .82$, $.86, .77, .73$ and .91

respectively). Six-week

test-retest correlations for

the scales and for the total

score ranged from .46 to

.82 .

The behavioural self-

efficacy scale and the

setting self-efficacy scale

both show good internal measures of self-efficacy

and with measures of child

temperament and

satisfaction with parenting.

The PTC discriminated

between clinic and non-

clinic mothers. In the

sample as a whole self- 
measured: behavioural

self-efficacy and setting

self-efficacy.

group, $n=79$ ).

\section{6-item instrument}

designed to assess

parenting efficacy in the

Guimond, Wilcox, \& context of early

Lamorey (2008) intervention. Two

dimensions are measured:

Guimond, Wilcox
Lamorey (2008) group, $n=45$ ) and non-

clinic mothers from the

community (non-clinic consistency $(\alpha=.97$ and

91 respectively).

Parenting Self-Efficacy

Scale (EIPSES)
The EIPSES has been

studied with the primary

female caregivers of 117

infants and toddlers (3-34

months) receiving early

intervention services.
The parent outcome

expectations scale,

competency scale, and

full-scale score showed

moderate to acceptable

consistency $(\alpha=.64, .75$, efficacy measures were

significant predictors of

maternal discipline style

after controlling for other

parent, child and risk

factors. Of the self-

efficacy variables

behavioural self-efficacy

was the best predictor of

mothers' discipline style.

The EIPSES total and

parent-outcome

expectations scale

converged with measures

of child receptive

communication and 
Parent outcome

expectations and parent

competence.

Me as a Parent (MaaP)

Hamilton, Matthews,

\& Crawford (2012)

personal agency, self-
management, and self-
sufficiency.

The MaaP has been

studied with parents (220

mothers, 80 fathers) of

infants (6 months to 2

years) through to young

adolescents (11-15 years). and .80 respectively). 


\begin{tabular}{|c|c|c|c|c|}
\hline Checklist (PCSC) & to measure practitioner's & studied with 300 general & internal consistency $(\alpha=$ & significant increase after \\
\hline Turner and Sanders & self-efficacy or confidence & medical practitioners who & $.92)$ & participating in Triple $\mathrm{P}$ \\
\hline (1999 cited in & in conducting behavioural & volunteered to participate & & Provider Training Courses. \\
\hline Sanders, Murphy- & family interventions with & Triple P Provider Training & & Participants of this training \\
\hline Brennan, \& & parents. This checklist & Courses. & & have been observed to \\
\hline McAuliffe, 2003) & contains items assessing & & & show significantly greater \\
\hline & perceived proficiency in & & & use of targeted parent \\
\hline & core skills including & & & consultation skills than \\
\hline & assessment, active skills & & & untrained GPs (Sanders, \\
\hline & training, dealing with & & & Tully, Turner, Maher, \& \\
\hline & process issues and clinical & & & McAuliffe, 2003). \\
\hline & application of positive & & & \\
\hline & parenting strategies. & & & \\
\hline
\end{tabular}




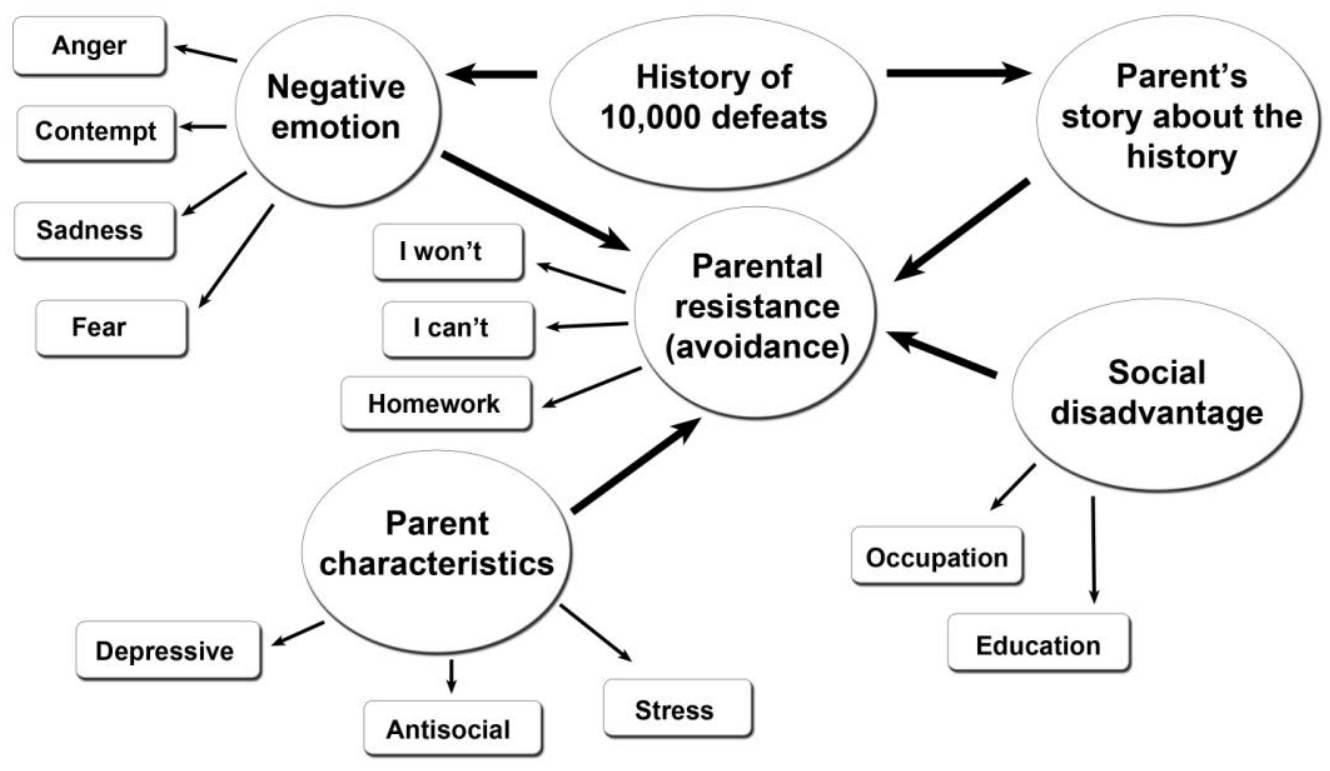

Figure 1. A model of parental resistance. Adapted from "A functional analysis of resistance during parent training therapy,” by G. R. Patterson and P. Chamberlain, 1994, Clinical Psychology: Science and Practice, 1, p. 55. Copyright 1994 by the American Psychological Association. 


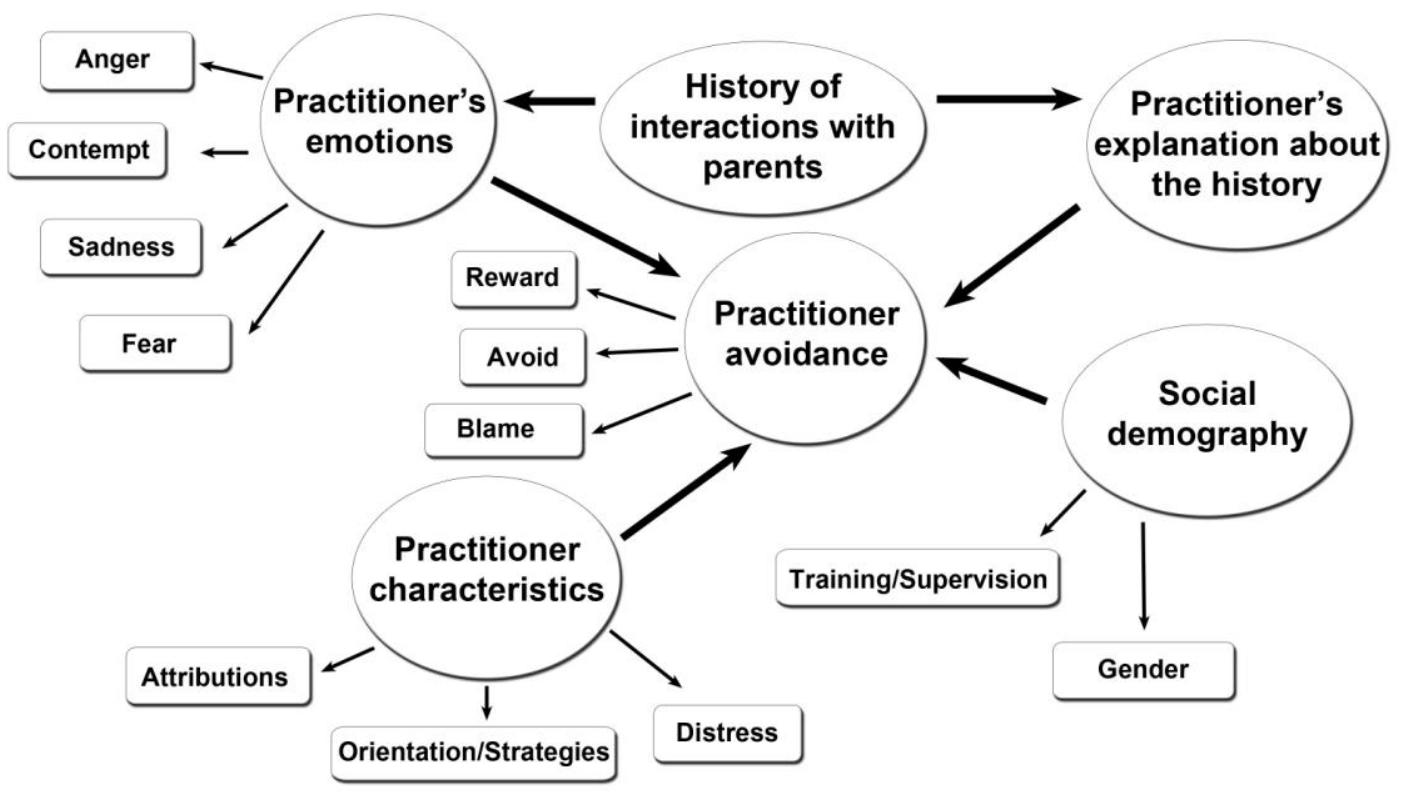

Figure 2. A model of practitioner avoidance. 